\title{
Spontaneous disappearance of severe latex allergy in an adult
}

Ambulatorio di Allergologia, Clinica San Carlo, Paderno Dugnano (MI), Italy

\author{
KEYWORDS \\ latex allergy; desensitization; \\ skin testing; IgE; anaphylaxis; \\ contact allergy \\ Corresponding author \\ Riccardo Asero \\ Ambulatorio di Allergologia, \\ Clinica San Carlo \\ Via Ospedale 21 \\ 20037 Paderno Dugnano (MI), Italia \\ E-mail: r.asero@libero.it
}

\section{Doi}

10.23822/EurAnnACI.1764-1489.55

\section{To the Editor}

A 56 year-old woman was recently seen at this allergy center. The patient had been known since 1995 for severe natural rubber latex (NRL) allergy. At that time, she had experienced an episode of immediate anaphylaxis (dyspnea, generalized pruritus, hypotension, and tachycardia) after wearing latex gloves. That episode was treated by systemic corticosteroids, antihistamines, and beta-agonists in an Emergency Room. The subsequent allergy workup demonstrated a clear-cut reactivity on skin prick testing with both latex glove (by the prick-prick technique) and commercial NRL extract (ALK/Abellò, Lainate, Italy; $500 \mu \mathrm{g}$ protein $/ \mathrm{ml}$ ) with wheals whose mean diameters exceeded 10 mm. The SPT with the common seasonal and perennial airborne allergens showed moderate hypersensitivity to ragweed pollen. Severe NRL allergy was diagnosed, and the woman was recommended to avoid any contact with latex.
During the following years the woman experienced severe rhino-conjunctivitis whenever she entered a hospital department to visit an inpatient or when she had to undergo medical visits. Some surgical interventions were carried out successfully throughout the years strictly following latex-safe procedures.

About 3 years ago the patient entered in a hospital to visit the mother as an inpatient without any consequence. Further, about 6 months ago, while undergoing dental treatments the woman noticed that she had forgotten to remind the dentist about her latex allergy and that he was wearing latex gloves but, to her great surprise, she did not experience any adverse reaction. In view of these facts she asked for a control visit at this department. The SPT with the same commercial NRL extract scored negative while the mean wheal diameter induced by the positive control, histamine $10 \mathrm{mg} / \mathrm{ml}$, was $7 \mathrm{~mm}$; similarly, the measurement of latex-specific IgE by ImmunoCAP (Thermo Fisher Scientific) scored negative $(<0,10 \mathrm{kU} / \mathrm{L})$. A latex glove-wearing test 
did not cause any reaction. Based on these findings and on the absence of any reaction following the recent exposures to NRL, it was concluded that the patient was no longer sensitized to natural rubber latex proteins. Notably, ragweed hypersensitivity was still clearly detectable at the control visit, as shown by clear-cut positive SPT and a specific IgE level of $4,55 \mathrm{kU} / \mathrm{L}$.

\section{Discussion}

The disappearance of both hypersensitivity and clinical allergy to an allergen is a well-known phenomenon in children allergic to cow's milk and/or hen's egg who, in most cases, outgrow their allergic status (1). In contrast, hypersensitivities that develop subsequently both in children and in adults are considered to be life-long. To the best of our knowledge this is the first reported case of spontaneous disappearance of natural rubber latex hypersensitivity in an adult patient. It is generally accepted that the long-term absence of contact with an allergen may result in a gradual lowering of specific IgE levels to the point that both in-vitro and in-vivo diagnostic tests score negative at the first re-exposure. IgE-mediated beta-lactam allergy is a typical example in this sense. However, it is also well-known that the re-exposure during the in-vivo diagnostic procedures elicits a secondary immunologic reaction by memory B cells that leads to a clinically measurable re-sensitization status after a few weeks (2). The patient described here was possibly re-exposed to NRL during a hospital visit 3 years ago and certainly and massively re-exposed during the more recent dental therapeutic treatments. Nonetheless, she seems presently no-longer sensitized to NRL allergens. It is not possible to say how frequently spontaneous desensitization occurs in adults, nor whether this is a specific feature of NRL allergy or may happen also in patients with other food or respiratory allergies. Similarly, the mechanisms by which the patient got desensitized are unclear, although it could be hypothesized that in this case a population of specific regulatory $\mathrm{T}$ cells proliferated and got activated, leading to the disappearance of the IgE-mediated response to NRL. As a matter of fact, the specificity of this process for NRL was demonstrated by the significant persistent ragweed hypersensitivity.

In conclusion, this case report shows that in some patients NRL allergy may disappear. Patients with this type of allergy might undergo allergological re-evaluation if a long time has gone from the initial diagnosis.

\section{References}

1. Savage J, Johns CB. Food allergy: epidemiology and natural history. Immunol Allergy Clin North Am 2015; 35:45-59.

2. Blanca M1, Romano A, Torres MJ, Férnandez J, Mayorga C, Rodriguez J, Demoly P, Bousquet PJ, Merk HF, Sanz ML, Ott H, Atanasković-Marković M. Update on the evaluation of hypersensitivity reactions to betalactams. Allergy 2009; 64:183-193. 